\title{
Apresentação Simbólico e Linguagem entre Dilemas e Possibilidades Sócio-antropológicas
}

\author{
Edson Farias ${ }^{1}$
}

1 Pesquisador do CNPq. Professor do Departamento de Sociologia da Universidade de Brasília e do Programa de Pós-Graduação em Memória: Sociedade e Linguagem da Universidade Estadual do Sudoeste da Bahia. Líder do grupo de pesquisa Cultura, Memória e Desenvolvimento $(\mathrm{CMD} / \mathrm{UnB})$.

2 Uma versão preliminar desse dossiê foi apresentada à Mesa

Temática: o Simbólico, a Linguagem e as Ciências Sociais,

Fruto do ciclo de leituras realizados no Programa de Ensino Tutorial do Departamento de Sociologia da Universidade de Brasília (PET/SOL/UnB), entre 2009 e 2010, a proposta deste dossiê é levar à condição de objeto de conhecimento/reflexão os efeitos gerados no instante em que o simbólico e a linguagem são identificados enquanto dimensões imanentes à ontogênese e à filogênese do humano, logo, intrínsecas ao social ${ }^{2}$. Parte-se da premissa de que algo assim reivindica atenção tanto para a ontologia do social quanto às redefinições com desdobramentos sensíveis na concepção mesma do modo de cognição próprio às ciências sociais e, é evidente, nos limites e teores da forma mesma do saber/fazer sócio-antropológicos.

Ora, a herança deixada pelos clássicos das nossas disciplinas protocolou a cognição por parte de um eu epistêmico, tendo por contrapartida o trabalho enquanto mediação entre a consciência e a natureza, como dimensão inalienável do ser historicosocial. Restringíssemo-nos aos heróis civilizadores das ciências sociais - em particular Marx, Durkheim e Weber -, encontraremos em seus respectivos legados o postulado a respeito de que o destino humano resulta do seu próprio fazer e este se encontra em sintonia com a intencionalidade inerente às realizações com as quais a espécie não apenas abre caminhos, mas - principalmente - os pavimenta enquanto curso (s) histórico (s). Neste sentido, autorrealização e inteligência foram tomados como aspectos inquestionáveis do conjunto humano e de sua fidelidade ao impulso à transformação perma- 
coordenada por Edson Farias, durante XIV Seminário Interno de Pesquisa do Grupo Cultura, Memória e Desenvolvimento (CMD)

- UnB, Brasília, 20 a 22 de julho de 2011.

3 Visando discutir este nexo entre o mito faústico da modernidade e as ciências sociais, ao longo da trajetória de leituras no PET/SOL nos ativemos ao livro Doutor Fausto, de Thomas Mann.

4 NISBET, Robert. $L a$ Tradition Sociologique. Paris: Press Universitaires de France, 1984, p.20-22

5 HAWTHORN, Geoffrey. Iluminismo e Desespero: uma história da sociologia. Rio de Janeiro: Paz e Terra, 1982. nente, apesar da opacidade dos mecanismos propulsores, reguladores e dos obstáculos a essa mesma dinâmica.

Assim, as ciências sociais não somente corroboram a narrativa épica de uma humanidade heróica por ser capaz de potencializar seus dotes cognitivos e fabris à luz da mediação intencional em que manifesta a perspicácia com a qual vence dificuldades inerentes à própria trajetória; antes, essas mesmas disciplinas se tornaram uma reserva, um nicho decisivo de guarda e propagação dessa narrativa e, logo, do sentido nela tecido e da moralidade que lhe é correlata ${ }^{3}$.

Algo esse curioso de ser notado, afinal - simultaneamente - o advento das disciplinas sócio-antropológicas ocorreu à contramão das certezas do ente reflexivo antropológico, na medida em que em entre os círculos intelectuais ocupados desse ramo do saber, cedo foi desperta a desconfiança quanto ao primado do autodomínio e mesmo das suas potências de controle/instrumentalização da natureza externa ${ }^{4}$. Ou seja. Ao evocar "forças impessoais", ainda que mundanas e inter-humanas, as ciências sociais estiveram no lado oposto do credo humanista ilustrado sobre a vocação antropocêntrica para a emancipação ante as determinações. Mais ainda. Estes ramos disciplinares nasceram de indagações intermináveis, efervescidas desde o século XVII europeu, simultaneamente nos planos político e intelectual, acerca da dialética entre instinto e instituição, vontade e normatividade, natural e artificial/cultural/ civilizacional. Disjunções estas cuja díade opositiva indivíduo e sociedade tanto figura quanto traduz ${ }^{5}$.

Nota-se, portanto, considerando a importância gozada por essa mesma díade, seja nos fazeres seja nos discursos dos cientistas sociais ainda hoje, o quanto no legado dos clássicos está embutido um dilema até agora estruturante da atitude cognoscitiva desenvolvida entre nós (das ciências sociais).

De um lado, mesmo que de modo silencioso (ou até mesmo por isto), somos cúmplices do modelo das filosofias da consciência com seu ponto axial fundado na antecedência do conhecimento (inerente ao intelecto) em relação ao mundo, apreendido como objeto à maneira de uma exterioridade a ser possuída, do qual deveremos nos apossar, com a finalidade de manipular. De outro, estendem-se os efeitos de uma concepção de racionalidade comprometida com o mundo e este é plasmado na figura de uma trama caracterizada pela relacionalidade corpórea e expressiva, apenas passível de ser apreendida e perscrutada no movimento em que se a concebe 
como estrutura, isto é, um arranjo inteligível de partes recíprocas e tão-somente significativas no escopo desse mesmo entretido. Estrutura esta não superior, tampouco redutível às estruturas físicas e biológicas. Tratando-se, sim, de estruturas psíquicas, compreensivas.

Sem dúvida, coube ao estruturalismo em geral, e à contribuição lévistraussiana em particular, no âmbito das ciências sociais, radicalizar o que as intervenções neokantianas (a exemplo das de Saussure e Cassirer) sublinharam na passagem do século XIX para o XX; a saber, a natureza simbólica desta estrutura em que se encerram as experiências das reciprocidades humanas. Somos tributários do estruturalismo quanto à deflagração sistemática de enunciados teóricos cuja repercussão começa por alterar o entendimento a respeito do social e, logo, por pressionar a poética sócio-antropológica. A este respeito, vale recordar que - na angulação estruturalista - a categoria de estrutura compreende a síntese das transformações responsáveis pela passagem de uma a outra variante. Se tal sintaxe explica o número restrito das possibilidades do modelo teórico, ao mesmo tempo indica o quanto a categoria de estrutura se impõe a de organização. Isto, em virtude de esta última apenas se tornar inteligível na medida em que a estrutura a explicita enquanto um caso particular entre os diversos de uma configuração. Algo assim sinaliza que, para tal inteligibilidade ocorrer, é urgente aos elementos que compõem o sistema a variação de acordo com as regras internas coercitivas do sistema mesmo, delimitando o número das transformações e estas obedecem à lógica que leva em conta as possibilidades contextuais. Por exemplo, quando uma sociedade retoma uma estrutura mítica, esta é recriada à luz das contradições de uma atualidade, de uma contingência. Portanto, a produção simbólica é parte inalienável mesmo da realidade sobre qual ela se rebate e confere sentido. A solução encontrada pela obra de Lévi-Strauss se deu a partir da superação do isolamento da contingência individual e histórica pelos empreendimentos de comparação e sistematização:

O sistema é ainda restrito, porém é necessário, assim como é necessário o uso de ciências diversas. Pouco a pouco o sistema deve estender-se para dominar o acontecimento. Às ciências e à relação entre as várias estruturas científicas serão confiadas à superação da individualizada solidão histórica. Somente deste modo a ciência é 'objetiva : porquanto 
6 PACI, Enzo (1970). "Antropologia estrutural e fenomenologia" In LIMA, Luis (1970). O Estruturalismo de

Lévi-Strauss. Petrópolis (RJ): Vozes, p.95.

7 Coube a Mauss, na

França, inaugurar a primeira cadeira em etnologia no Collège de France, em 1935. No projeto metodológico do "fato social total" o relevo é dado à interiorização por parte dos indivíduos das coordenadas da sociedade, tornando-se este $o$ vetor inconsciente (estrutural-estruturante) das personalidades. Em outros termos, a partir da acepção da "troca", da dádiva, como espécie de marco zero da interação humana, o esquema do "fato social total" maussiano detém caráter tridimensional; esta tridimensionalidade, de acordo com Lévi-Strauss, faz coincidir a "dimensão propria- supera a experiência singular e porquanto se serve de modelos formais." ${ }^{\circ}$

Mas é também verdade que o sentido de totalidade que aspira Lévi-Strauss é encontrada no projeto antropológico do estudo do "fato social total", por Marcel Mauss. Projeto que se abstém do encapsulamento com o que Durkheim teria conduzido a sociologia e promove a aproximação com os saberes psicológicos, fisiológicos, históricos e geográficos com finalidade de abarcar a complexidade dos fenômenos em suas dimensões jurídicas, econômicas, morfológicas, estéticas que estariam inter-relacionadas funcionalmente ${ }^{8}$. Atingir a totalidade, por sua vez, impõe a inserção da idéia de inconsciente, categoria presente na obra de Mauss ao tratar da mediação entre a subjetividade e o objeto; ou seja, o inconsciente diz respeito à forma dotada da capacidade de realizar o entendimento entre o mim e o outro, na medida em que antecede a ambos e possuem os materiais elementares da comunicação. Como observa Renzi, em lugar do reconhecimento intersubjetivo do outro, Lévi-Strauss privilegiou o inconsciente como "estrutura da estrutura", para dar nitidez ao que seriam as "arquiteturas lógicas" da sociedade, do homem e do tempo, perseverando suas leis de combinações categoriais a despeito dos sujeitos pensantes e das ondulações históricas9.

Porém, este tributo porta suas antinomias, tornando-se até aporético. Afinal, algumas interrogações emergiram no andamento da popularidade adquirida pelo estruturalismo. Para os nossos interesses, aqui, duas têm especial relevo.

A primeira corresponde à reatualização da díade indivíduo e sociedade no esquema da estrutura simbólica. Não é demais lembrar: enquanto fator universal demiúrgico, esta estrutura ultrapassa qualquer parcialidade, mas as engendra, espiritualizando-as, fazendo-as significar e as tornando significantes. Enfim, se dispensa a figura do "eu", reduzindo-o a mero executor do código cultural, ironicamente, repõe a ruptura entre o inteligível e o natural. É verdade que, indo além da separação entre individual e coletivo, tal como proposta por Durkheim, afinal não mais estão o inteligível e o entendimento do lado da intencionalidade; agora, ambos se engajam em uma estrutura autorreferente, dissociando-se do claustro da consciência e do eu epistêmico. Porém, igualmente, nessa mesma estrutura ambos se desencarnam, por não ser ela relativa ao escopo do tramado corpóreo em suas circunstâncias e idiossincrasias, mas compondo um domínio 
mente sociológica com seus múltiplos aspectos sincrônicos; a dimensão histórica, ou diacrônica; e, finalmente, a dimensão fisio-psicológica”. LÉVI-STRAUSS, Claude (1974). "Introdução" In: MAUSS, Marcel: Sociologia e Antropologia. SP: EPU e Edusp, 1974, p.14.

8 LÉVI-STRAUSS, Claude (1970). "Aula inaugural" In: Luis Costa Lima, Op. cit., p.48.

9 RAZZI, Emilio (1970). "Sobre a noção do inconsciente em Lévi-Strauss" In: Luis Costa Lima. Op. cit., p.113.

10 GIDDENS, Anthony. A Constituição da Sociedade. São Paulo: Martins Fontes, 1989, p.17-22.

11 GARFINKEL, Harold. Study of Ethomethodology. New York: legiferante coerente e igual a si mesmo.

A outra interrogação, em nítida afinidade com a anterior, volta-se à ausência de historicidade no tocante à concepção de estrutura simbólica pelo estruturalismo. Engendrando diferentes ecologias, esta estrutura promoveria e, com isto, se proporcionaria variações, contudo, sem conhecer qualquer transformação. Muitas das insatisfações decorrentes dessa perspectiva não estiveram em favor da acolhida de uma prerrogativa mudancista levantada em nome do postulado evolutivo-desenvolvimentista ou do credo teleológico de um fim a ser cumprido. A implicação estava diretamente vinculada à negligência observada em relação ao problema da recursividade desta estrutura em meio à contingência. O problema já havia ocupado o interesse de Talcott Parsons, em A Estrutura da Ação Social e, ainda, em $O$ Sistema Social, no instante em que o autor se aplica em gerar um modelo analítico no qual quer apreender o seguinte: afrontada na situação pelas incessantes correntes do acaso, com efeitos sobre a atenção e as escolhas dos entes biológicos capacitados à decisão, a norma se antecipa estruturando a subjetividade da agência, fecundando assim o corpo mediante a inserção de expectativas tanto norteadoras quanto coordenativas das atitudes. Isto, ao inscrever os indivíduos no sistema dos lugares ator-papel. Embora possa ser julgada insatisfatória, a solução parsoniana evidencia a percepção diante da lacuna presente aos esquemas estruturalistas - a mesma lacuna que antes Mauss quis sanar; vácuo constituído pela ausência da vontade e da intencionalidade no que concerne à recursividade da estrutura. Para falar à maneira de Giddens ${ }^{10}$, o que se está questionando é como há de se fechar os olhos à imperiosidade de articular a longevidade da estrutura à maneira como essa fornece recursos ao prosseguimento intencionado da vida.

A esta altura estava evidente no horizonte das ciências sociais a aproximação de uma teoria que retomasse o velho problema aristotélico a respeito das tendências (hexis). Uma versão inicial desta reorientação fora proposta no esquema etnometodológico de Garfinkel ${ }^{11}$, quando este autor se volta para o tema da simbolização, mas relacionando-o às competências práticas dos agentes de se constituírem narrativamente, em situações interativas nas quais ocorrem a tradução e interpretação de signos por outros afins. Em lugar, portanto, da ênfase no plano das representações, como legou a matriz das teorias da ação ou a derivação normativista sistêmica de Parsons, importava à pragmática da agência 
Sage, 1991.

12 BOURDIEU, Pierre. A Distinção. Porto Alegre: Zouk, 2007.

13 PASSERON, Jean- se apresentar e afirmar. Desse modo, para Garfinkel, interessa os usos dos símbolos pelos agentes na estruturação da própria conduta e na reposição atualizada da sua identidade nos círculos dialógicos e interacionais dos quais participa.

Se uma contribuição como essa se fizera decisiva à formatação de modelos construtivistas em que se ancorarão as teorias das disposições corporais, a tônica acentuada na reflexividade intencional do agente resultou em limitar o alcance do modelo; sobretudo, quando se teria que relacionar a economia emocional psíquica com o plano sócio-sistêmico a fim de propor o nexo da competência cognitiva e intencional do agente com o quadro histórico-estrutural, no sentido de analisar e conceituar os usos de si e das coisas no prosseguir estruturado das conduções da vida.

Chegamos, assim, ao ponto de partida do ciclo de leituras que iniciamos no PET/SOL, em abril de 2009, com o livro A Distinção: crítica social do julgamento, de Pierre Bourdieu ${ }^{12}$. Obra que parece anunciar a fase madura do autor; nela, deságuam interlocuções e debates internos à teoria social no que concerne à conexão entre agência e estrutura social. Correlacionando as sociologias da cultura e da educação, justamente, Bourdieu procura apreen- der e conceituar como prosseguem positivamente distinções sutis inerentes ao mundo social, isto ao fazer cúmplices pulsões e fronteiras institucionais mediante a intervenção de saberes que, por sua vez, habilitam ou não os corpos aos trânsitos significativos nas vias dos mesmos espaços da socialidade. Mas, algo assim se faz quando os corpos atualizam cognitivamente os mesmos espaços em suas condutas movidas pelo conhecimento e em busca de reconhecimento, acionando para isto estratégias tácitas de interpelação e alocação de recursos valorados (capitais) em graus diferenciadamente hierarquizados nesses mesmos espaços sociais de possibilidades (os campos).

Olhando para trás, no ponto em que ora nos encontramos, talvez devêssemos concluir que a obra de Bourdieu deveria ter encerrado o percurso de leituras. Isto porque, depois de percorrermos o elenco de textos debatidos ao longo dos dois anos, A Distinção fecharia o ciclo e, ao mesmo tempo, a recepção do livro teria maior respaldo. No entanto, suspeito que a opção feita mostrou-se mais acertada, porque ao identificarmos em $A$ Distinção uma miríade de questões relacionadas à teoria das disposições, pudemos paulatinamente desdobrar essas questões no movimento das interfaces do esquema 
-Claude. O Raciocínio Sociológico: o espaço não-popperiano do raciocínio natural. Petrópolis (RJ): Vozes, 1995.

14 CASSIRER, Ernst. Ensaio sobre o Homem: uma introdução a uma filosofia da cultura humana. São Paulo: Martins Fontes, 1994. bourdiano, direta ou indiretamente, com contribuições que repercutiram na consideração da ordem simbólica e da linguagem na redefinição ontológica do social e, logo, na reacomodação epistemológica das ciências sociais.

Assim, a título de retomar as linhas gerais do trajeto de leituras com a finalidade de tornar explícito o eixo que o norteou, focalizaremos sumariamente os textos tratados e que estiveram dispostos em interlocução com o ponto de partida ocupado por $A$ Distinção.

A leitura de O Raciocínio Sociológico, de Jean-Claude Passeron ${ }^{13}$, cumpriu a tarefa de localizar a aplicação analítica realizada no texto de Bourdieu no quadro intelectual e institucional do projeto de sociologia calcado na reflexividade - mais propriamente, na reflexividade incessante da razão, de acordo com Bachelard. Projeto este que torna imperioso a qualquer exercício de objetivação das relações instauradoras do mundo social ater-se à trama própria em que o agente da objetivação sociológica se torna uma posição de sujeito cognoscente e afetivo. Denominando-a de "vigilância epistemológica", este projeto/principio procedimental focaliza a realização sociológica como um entre outros regimes de verdade no instante em que intervém em favor da polissemia. Isto é, da ampliação das possibilidades de saber e dizer o "mundo", enfim, de alargar as "coisas ditas" acerca dos mundos e das experiências que o atualizam.

A contribuição de Passeron se fez decisiva por desvelar a condição discursiva do fazer sociológico. Ao mesmo tempo, esse desvelamento tanto resgata o condicionamento simbólico das práticas quanto problematiza a antecedência estrutural-simbólica à medida que a remete ao plano da expressividade e da comunicação de atores em dinâmicas de lutas sociais, de disputas posicionadas por posições.

A partir desta leitura, dois desdobramentos foram incontornáveis. Primeiro, acompanhar como o estatuto do simbólico irá ocupar lugar estratégico na antropologia filosófica. Posição conquistada no momento em que, nos rastros de Vico, caberia estreitar o conhecimento a respeito de como se ergueu esse revestimento simbólico, composto pela camada dos sentidos, por intermédio do qual a humanidade instaurou seus mundos possíveis, artificiais. A leitura do livro Ensaio sobre o Homem, de Cassirer ${ }^{14}$, exatamente, procurou servir a esse objetivo.

Já o segundo desdobramento seria contextualizar em uma espécie de genealogia e arqueologia das idéias a tessitura do simbólico, mais a expressão e 
15 TODOROV, Tzvetan. As Teorias do Símbolo. Campinas (SP): Papirus.1996..

16 BATESON, Gregory. Naven. São Paulo: Edusp, 2008. a comunicação, enquanto objeto de conhecimento e reflexão na história do pensamento ocidental. Por isso se fez o recurso às Teorias do Simbólico, de Todorov ${ }^{15}$

Diante do encaminhamento até então realizado, a opção por ler o Naven, de Gregory Bateson ${ }^{16}$, era rastrear no fazer das ciências sociais as condições epistemológicas como um modo de cognição para o qual a realidade vivida e percebida é significativa na medida em que implica no trabalho simbólico-expressivo de linguagens como perfomances. Nesse sentido, o dublê de etnografia antropológica e de teoria social, algo que dá originalidade à obra betesoniana, mostrou-se mais que oportuna, pois não apenas flagra e discute esse trabalho da linguagem; mas avança na direção de um caminho espinhoso a quem nele se aventura: procurar esse trabalho simbólico na formação das disposições que concretizam, porque realizam, um dado temperamento cultural.

Com a leitura de As Palavras e as Coisas, de Foucault, preenchia-se a o vazio que tomara de assalto o trajeto realizado, a saber, ler e discutir a condição representacional, discursiva, do simbólico. E, ao apreender essa condição discursiva, sublinhar em seu traço arbitrário positivador de objetos e sujei- tos, a problemática do poder/saber como a contrapartida inalienável dos eventos e processos de significação.

Entretanto, no instante mesmo em que a contribuição foucaultiana assinalava o desfecho do percurso de leituras realizado, igualmente sinalizava para as lacunas abertas na e pela dinâmica das discussões. Fendas estas correspondentes à aproximação, uma vez mais, com a problemática do simbólico, porém tendo de levar conta sua extensividade para além do plano discursivo. Acredito que o amplo horizonte de questões que ora se abre diante da mesma problematização chama atenção para o terreno sempre mais a ser pisado e fecundado no fazer sócio-antropológico: investir na natureza simbólica das disposições corporais e, ao mesmo tempo, exercitar o conhecimento da tessitura biopsíquica das simbolizações.

Contudo, essas problematizações excediam os limites postos ao ciclo de leituras iniciado em 2009, pois que suscitam outros encontros para novos esforços de estudo e reflexão. Assim, os quatro textos que compõem o dossiê oferecem perspectivas criativas, originais, dos temas que animaram o debate fomentado nos dois anos de encontros semanais, durante as reuniões do PET/SOL. 
Em Bateson, Velázquez da Antropologia: reflexões acerca do olhar moderno a partir de Michel Foucault, Maurício Piatti Lages evoca tanto o conceito de "epistémê" quanto às inquietações provocadas em Foucault pelo quadro As Meninas, do pintor espanhol Velaquez, para se aventurar nas ambiguidades de um clássico da literatura antropológica. Deixando-se levar pelo desconstrutivismo que marcou a atitude da chamada onda pós-moderna na Antropologia, encabeçada por autores como de James Clifford e George Marcus, nos interstícios da célebre obra de Bateson, O Naven, Lages busca as fissuras que o conduzam para além da retórica realista ocupada com a descrição de um ritual de um povo exótico da Polinésia. O que ele encontra, porém, o desconcerta, afinal, o próprio antropólogo deixa patente seu desconforto com o propenso distanciamento etnográfico; sua empreita etnológica mostra-se, bem mais, uma dobra sobre o seu ponto de partida epistemológico, o ocidente com seus mitos, entre os quais, o da objetividade do conhecimento científico.

Já Lucas Marquês, em A Realidade da Fantasia e a Fantasia da Realidade: Borges e a fenda foucaultiana, deixa-se levar imaginativamente até os efeitos da leitura da obra do escritor argentino
Jorge Luis Borges sobre Michel Foucault, a ponto de indagar o quanto a escrita de As Palavras e as Coisas responde ao impacto provocado, nele, pela literatura borgiana. Assim, ao recuperar o tema das "heterotopias" como espécie de fendas pelas quais se dá o deslize de uma épistémè à outra, no livro do filósofo francês, Marquês se ocupa do tratamento conferido pelos diferentes regimes de verdade, mas da perspectiva dessas liminaridades transitivas, as fendas, nas quais as distintas certezas epistêmicas manifestam sua incompletude, desvelam-se frágeis e arbitrárias.

Às voltas com problemas metodológicos surgidos na própria experiência de campo, Nilton Aguillar Costa se volta ao dueto entre as ideias de ordinário e extraordinário, tão celeumático quanto, por isso mesmo, rico em consequências filosóficas, teóricas e analíticas no pensamento social. Ele se coloca - e por tabela, também a nós, leitores - diante de alguns impasses a respeito do estatuto ontológico do social no pensar e fazer antropológicos, no instante em que a atitude razoável entre os antropólogos parece estar em destacar o "extraordinário" como a chave com a qual se acessa ao enigma de um determinado social. Traduzindo o referido dueto na outra polêmica disjuntiva, normal e anormal, Costa 
aproxima o olhar conferido por Bateson ao ritual do "naven" do modo como ele próprio encarou a questão do "surto psicótico" na sua pesquisa sobre os significados da loucura feminina. Em um e outro caso, àquilo a que se aplica sua argumentação, sem incorrer na negligência, corresponde à posição natural com que ambos os intérpretes não fizeram do "extraordinário" o ponto elucidativo do social.

No ensaio de Pedro Martins de Menezes, $\mathrm{O} S \mathrm{Sa}$ tanismo Metodológico: pode um saber compreensivo deixar de se compreender?, uma vez mais a condição de discurso, logo de linguagem e de modo simbólico de expressão, das ciências sociais, em particular da sociologia, é requisitada para, logo em seguida, tornar-se alvo de um questionamento dilacerante. Não só da disciplina, diga-se de passagem, mas de todos nós que nos aplicamos a esse exercício de conhecimento, incluindo o próprio autor do ensaio. $\mathrm{O}$ traço esgarçador inerente ao argumento desenvolvido por Menezes se refere ao seguinte dilema hamletiano: ou deixa-se, o sociólogo, perder na alienação completa para atender o primado de uma objetividade que, em sua finalidade canina à prerrogativa da neutralidade axiológica, permanece na comodidade de tão somente espelhar fotograficamente o "real"; ou escapa - o mesmo sociólogo - para o casulo do próprio nicho, virando às costas ao tal "real" e devota-se, quase tomado por uma cólera diabólica, a elaborar o seu real particular. E se caso haja uma saída? - e Pedro Menezes parece acreditar que sim -, talvez esteja na percepção intrínseca à própria linguagem. Com ela, sabemos, que toda mimeses não pode fugir a sina de ser também criação, na inversa medida em que qualquer criação não se faz em um vácuo. 